\title{
Challenges in creating a 3D participatory platform for urban development
}

\author{
Thibaud Chassin $^{\mathrm{a} \mathrm{b}^{*}}$, Jens Ingensand ${ }^{\mathrm{b}}$, Maryam Lotfian ${ }^{\mathrm{b}} \mathrm{c}$, Olivier Ertz $^{\mathrm{b}}$, Florent Joerin ${ }^{\mathrm{b} d}$ \\ ${ }^{a}$ EPFL, LASIG, CH-1015 Lausanne, Switzerland, thibaud.chassin@epfl.ch \\ ${ }^{b}$ University of Applied Sciences Western Switzerland (HES-SO), Yverdon-Les-Bains Switzerland, jens.ingensand@heig-vd.ch \\ ${ }^{c}$ Politecnico di Milano, Piazza Leonardo da Vinci 32, 20133 Milano, Italy, maryam.lotfian@polimi.it \\ ${ }^{d}$ Lausanne University, Lausanne, Switzerland, florent.joerin@unil.ch \\ * Corresponding author
}

\begin{abstract}
This paper aims at underling difficulties regarding the establishment of citizen engagement processes. The specificity of citizen engagement processes lies in their evolution over time where objectives, constraints, and latitudes of a given project influence the relevance of the tools offered to citizens. Three categories of urban projects (transurban, major metropolitan, architectural design) have been described. These classes range from a local space with short deadlines to a regional space spread over several decades. Furthermore, the use of 3D platforms for a broad public is influenced by the users' preferences, perception, and expertise. Throughout this study, major challenges that have been experienced during the design a 3D participatory platform are identified. They range from the issues of implementing adequate tools according to the project (temporal and spatial scalability), the participation forms (passive, consultative or interactive), to the difficulties of convincing the authorities to use new bottom-up methods. Finally, a conceptual framework for the creation of a 3D participatory platform has been introduced. It can be summarized by three major steps: (1) Meeting the needs of a decision maker, (2) Designing the participation tool in accordance with the context, (3) Translating collected raw data in order to respond to the initial request.
\end{abstract}

Keywords: public participation, citizen engagement, urban planning, 3D virtual environment, decision making

\section{Introduction}

In 2014 , more than $50 \%$ of the global population was living in urban areas. In 2050, this number will likely climb to $66 \%$, adding another 2.5 billion inhabitants to cities (United Nations, 2014). To meet this growth current practices regarding urban planning have to change in order to be more sustainable. All around the world, several programs aim at creating digital cities by taking into account concepts such as walkability, connectivity, mixed environments, etc. Unfortunately, public authorities are often designing and creating urban projects without any involvement of the residents. This regularly leads to a more or less violent rejection and/or opposition from the public (Subra, 2014).

Classic participatory initiatives arose from the cited context. However, such initiatives are often less suited for earning the approval of the population due to the fact that shareholders participate in interminable workshops usually held during weekdays. Our past experience with participatory workshops show that participants are mostly elderly people or/ and vigorous opponents.

Information and Communication Technologies (ICT) are one solution to broaden the potential public and to create a sustainable relationship and exchange between the government and the citizens. The concept of digital cities provides new means of bringing together the public and authorities through the use of Volunteered Geographic Information (VGI) platforms such as OpenStreetMap (openstreetmap.org), a worldwide map updated by the public where citizen are used as sensors or data producers (Goodchild, 2007). In contrast to the VGI's unoriented data production, Public Participatory Geographical Information Systems (PPGIS) aspire to introduce citizen engagement in decision making processes. Several examples exist such as FixMyStreet (fixmystreet.com) a British web application to report issues in the streets such as graffiti or cracked paving slabs. Another example is Signalez-nous (mapnv.ch/signalez/interface) a Swiss website that allows citizens to report broken street lamps, etc. Based on these concepts new PPGIS platforms addressing urban planning and decision making have emerged. Some examples include Carticipe (carticipe.net), used in several French cities (Avignon, Paris, Strasbourg, etc.) or Maptionnaire (maptionnaire.com) which offers a map survey oriented to gather citizens' insights (Stockholm, New York, etc.). Others are implemented for research purposes such as Argumap (Rinner, 1999), a PPGIS platform used in Brazil (Bugs \& al., 2010) or Pocitové mapy (pocitovemapy.cz) an emotional mapping platform used in the Czech Republic (Pánek, 2018).

Up to now the vast majority of these systems are based on a two-dimensional representation of the territory. We argue that the third dimension is important for territorial decision making since it allows for the visualization of spatial phenomena such as volumes of buildings, the slope of the terrain or infrastructure that passes under or 
over other infrastructure. Biljecki \& al. (2015) have identified several studies which intent to design and use 3D platforms, but generally, the target users of these tools are experts. Very few tools involving 3D are focussing on citizens as users (Alatalo \& al., 2017). One reason for this fact might be the availability of $3 \mathrm{D}$ data, the difficulty to build usable 3D platforms, or concerns about using virtual environments for laypersons.

This paper aims at understanding why $3 \mathrm{D}$ is less used by the broad public in the context of decision making platforms. Another goal is to identify challenges, referred as "C" in the following text, for the creation of 3D platforms for public participation. This paper is structured as follows: subsequently to this introduction, in the next two sections, we address the influence of the parameters scale and time in participatory processes. Thereafter we discuss the importance of human and user factors. A conceptual framework which addresses the design of a participatory platform is described in section five. Then, we analyze ways of tackling the identified challenges. Finally, we present our conclusions and outline perspectives for future development.

\section{Fitting the urban scale}

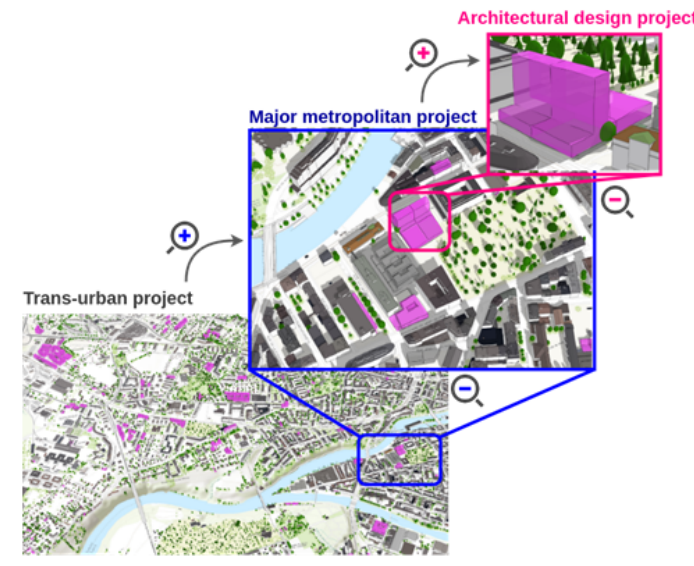

Figure 1. A visual depiction of the three urban project types trans-urban, major metropolitan and architectural design described by Arab (2007) and their relationships. This illustration is based on the 3D model of Geneva (sitg.maps.arcgis.com).

In her study, Arab (2007) describes three contrasting categories of urban projects (type A, B, C). Each of these categories has a specific temporal and spatial scale, ranging from a few years within a parcel to several decades in an urban area. The type A, thereafter referred as trans-urban project, stretches over long-term strategies regarding the reshaping of an urban area often composed by diverse cities. The $\mathrm{B}$ type, hereinafter called architectural design project, is more particular and focuses on a small parcel during a few years. The $\mathrm{C}$ type, the major metropolitan project, is more diverse, generally carried out during more than one decade. These programs aspire to reshape one or several districts of a city. Each pattern of projects affects a corresponding scale from the urban morphology: the trans-urban type at city macroscale, the architectural design type at neighborhood-scale and the major metropolitan type at micro-scale (cf. Fig. 1).
However, in her paper Arab (2007) does not describe the relationship between these urban project archetypes. Fig. 1 illustrates the spatial extent of these types of projects. This means that generally an architectural design project is a measurable pattern of a major metropolitan program (more complex), and the latter is defined by directives dictated by a trans-urban project strategy. Furthermore, Fig. 1 highlights different perceptions according to the scale of the project type. Montello (1993) describes a terminology to define shifts in spatial scale : the Figural space is for objects smaller than the human body, the Vista space for areas that can be apprehended from a terrestrial viewpoint, the Environmental space is perceivable while moving about and the Geographical space for a territory which can only be understood via tools. Following this classification the trans-urban project is related to the Environmental space; the architectural design project can be associated with the Vista space; the major metropolitan project type is located at the border between Vista and Environmental space.

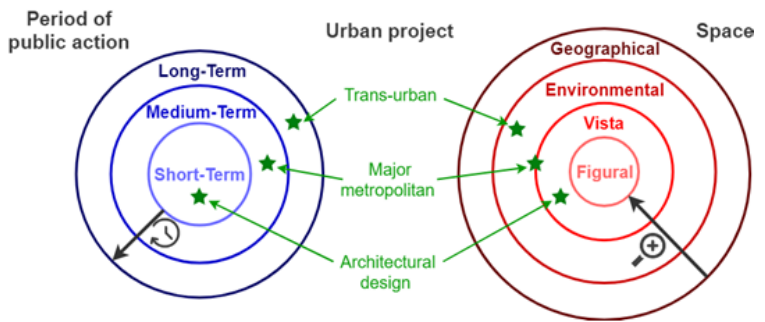

Figure 2. A conceptualization of the integration of the urban project types (trans-urban, major metropolitan, architectural design) described by (Arab, 2007) into the city time and space scale introduced by (Montello, 1993).

Fig. 2 gives an overview of spatial and temporal scale shifts aiming at visually apprehending these concept side by side. On the left, time is represented from the shortest in the center to the longest at the external boundary. On the right, spatial scales described by Montello (1993) are shown: from the less (larger scales) to the most perceivable (smaller scales). The architectural design type affecting one or a few buildings has a short implementation time and is included in the Vista space. The major metropolitan type is bound to a medium time period, rarely ranging over two decades. It has an established deadline. These projects are situated between the Vista and the Environmental space aim at transforming a district. The trans-urban project involves a long period of time, the terminology "horizon" is often used. It implies a reshaping of an urban area. These different patterns lead to the first challenge:

[C1] How to create a $3 D$ platform that is able to take into account different types of projects (trans-urban, major metropolitan, architectural design) with their own time and space distinctiveness?

Citizen contributions within participatory processes are therefore shaped by time and space scales related to a project type and its embedding in the range of urban projects. Moreover, the perception of a city is personal, incomplete and based on experience (Lynch, 1960). Users 
will consequently perform differently regarding mental reconstruction tasks of a city, by locating varied urban features depending on their cognition and knowl- edge. Chapon \& al. (2010) describe three categories of environments: (1) an unknown area, where only a few blurry features, generally corresponding to identitybuilding elements of a place (e.g. political buildings, tourist attractions), can be portrayed; (2) a loose known area, the reconstructed map contains structural elements (such as town halls, churches, main roads, shops) and their immediate surroundings, but its representation is still imprecise; (3) the acquired known area which contains rich information (such as toponyms, pathways), in addition to a personal grasping of the environment.

The citizens' perception is linked to their own appropriation of the territory build on a specific spatial scale. Location and dimension shifts, typical for urban projects, create a loss of reference points and thereby a feeling of disorientation. Based on these statements we define the following issue:

[C2] How to avoid user disorientation when navigating between project scales?

\section{Fitting the project temporal evolution}

While focusing on a specific project an evolution into its parameters can be observed over time. These settings include the latitude (the degree of freedom that citizen possess to influence a project), the definition (the maturity of a project in terms of specifications, etc), the limitations (constraints and objectives that are identified during the elaboration of a project), and the shareholders. For the development of an automobile industry project, (Midler, 1993) has established a link between the latitude of a project and its definition. Fig. 3 is based on these considerations where the project's flexibility decreases over time while its global knowledge grows (because of the integration of objectives and constraints). Moreover, disparity and convergence have been identified by Arab (2007) between project management theory and urban planning.

Several studies have considered the impact of public involvement regarding urban planning decision making (Arnstein 1969; Hart, 1992; Pretty, 1995; iap2, 2014). The typology used within our study is described by Pretty (1995): seven rungs are portrayed ranging from manipulative participation to self-mobilization. Three of these participation levels have been selected from their frequent use in citizen engagement to be linked to the dynamics of an industrial project: (1) Passive involvement mirrors unilateral dialogue from the authorities to the citizens aiming at an explanation of the decisions that have been taken. Arnstein (1969) has defined this rung as information, (2) Consultative participation depicts an exchange between the shareholders where "people's view" is potentially taken into account by the city's representatives, (3) Interactive participation out- lines the idea of co-design. In this case, a municipality works with its citizens to achieve and develop a project. Arnstein (1969) has labeled it partnership while the international association of public participation have defined it as collaboration (iap2, 2014) .

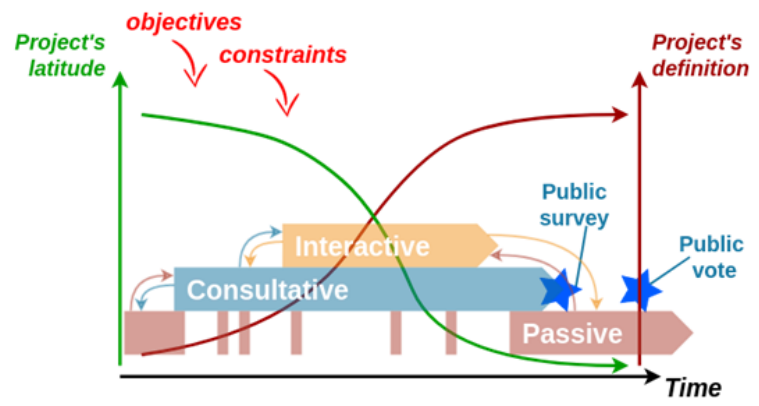

Figure 3. Augmentation of the industrial project dynamics over time introduced by (Midler, 1993) with citizen participation features located where they are the most efficient.

Figure 3 shows three temporal stages where the project's latitude and definition evolve over time. In the beginning, the project is not well defined yet. Passive participation (or information) is at this point the most suitable mean of communication since it allows public authorities to communicate about the idea of a new project. Once the public is informed it becomes possible to consult the citizens about several objectives or constraints of the project in order to understand the citizens' expectations. Thereafter a definition phase begins where the latitude decreases quickly. An interactive (or partnership) public involvement can be considered here as an opportunity for the public authorities' representatives to collaborate on the design of the proposal in order to take into account the insights of the citizens. During this phase, discontinuous passive communication can be done by the authorities when new challenges are identified (e.g. environmental policies or technical obstacles). Finally, once the definition of the project is completed, a public survey is scheduled. This survey is a legal matter in Switzerland, all documentation on the project must be provided to the public for 30 days by the authorities. During this period citizens have the possibility to approve or disapprove the project at a legal authority. Thereafter the design and the definition of the project cannot evolve anymore. It is the end of the consultative and interactive participation, despite the pursuit of the passive public involvement. Following the public survey, a vote is executed where the electorate accepts or reject the continuation of the project. The challenge linked to these processes is:

[C3] How to design platform functionalities that adapt to participation level shifts and new information that has been introduced during the evolution of a project?

\section{Fitting the public/ user}

Lange (2011) argued that the advancements accomplished in the field of virtual reality are sufficient to adopt such technologies to landscape and urban planning. Undoubtedly, challenges are still to be addressed, but 3D scenes can be considered mature enough to be shared to a broader public. However, the authorities are still reluctant to utilize such platforms online. The pretexts are numerous. For instance two 
Swiss cities (contacted by the authors) argued that the participation level of a $3 \mathrm{D}$ platform could decline or that the results could even be used against them. These arguments are not consistent with the results of several studies testifying the usefulness of the third dimension in communicating with the public by lowering the participation entry cost for the citizen, and easing the access to complex processes (Liao \& al., 2011; Çöltekin \& al., 2016). However, citizens are not effortlessly involved in these processes. In their study Evans-Cowley \& Hollander (2010) suggested that in a social network the number of "likes" can gather a social group against (or for) an urban project but it is laborious to make these "likes" visible public hearings. In addition, interactive scenes establish neutrality and transparency regarding the participation; a fact that cannot be addressed with static pictures that present an author's bias by the choice of quality, perspective, or viewpoints (Onitsuka \& al., 2018; Downes \& Lange, 2015; Méricskay, 2012). Moreover interactive maps are more effective and suited for complex tasks but require more time (Herman \& al., 2018). Based on these considerations we can identify the following question:

[C4] How to convince authorities that their accountability and reliability can be increased by a public participatory $3 D$ platform?

\section{The user navigation :}

Several studies (e.g. McCrae \& al., 2009; Bowman \& al., 1997; Moya \& al., 2014) have attempted to create 3D navigation metaphors based on the two aspects that balance navigation mechanisms in virtual environments: (1) movement (motion), (2) wayfinding (cognition) (Jankowski \& al., 2014). Mackinlay et al. (1990) and Jankowski \& Hachet (2015) listed some techniques from walking to flying analogies in an automated or manual mode. Each navigation method has its benefits and drawbacks. For instance, automated movement helps to ease the use of 3D scenes for laypersons, however, it reduces user engagement (Parush \& al., 2007). In contrast, experts prefer manual control due to higher accuracy and velocity (Moya \& al., 2014). Therefore, navigation relies on a user's past-experiences and preferences. Moreover, a city model contains numerous scales that motion depend upon. Based on this assump- tion, Zhang (2009) suggests a multi-scale displacement managed by an avatar changing in size: the taller, the faster the user can move through the virtual scene.

\section{The user perception:}

Numerous factors can guide a user to apprehend a virtual environment such as tips on the available features and their function, a "you are here" arrow, highlighted interactive elements, etc. One major challenge in $3 \mathrm{D}$ visualization is data overload leading to errors because of a loss of readability (Seipel, 2013; Juř́k \& al., 2016). To limit this lack, abstract representations are used (Alatalo $\&$ al., 2017). This conceptual depiction can be used to collect information (as insights, emotions, opinions or problems) and to empower a robust basis for discussion or communication aiming at a specific topic (Hayek, 2011). In contrast, photo-realistic models or experimental representations are more intuitive (Tutzauer \& Becker, 2016), linked to emotions (Newell \& Canessa, 2018) and considered to be more natural (Stachoň \& al., 2018). However, excessive realism leads to an uncanny feeling, therefore mixed representations combining abstraction and verism have proved their efficiency (Appleton \& Lovett, 2003; Lokka \& Çöltekin, 2018).

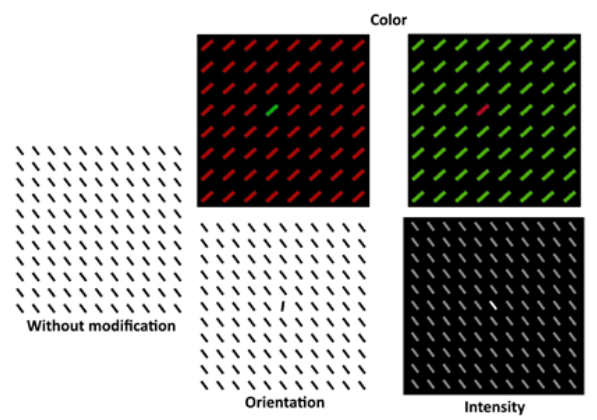

Figure 4. Pop-out effects created by color modification, intensity or orientation from (Martin, 2018) and (Chiaramonte, 2007).

To clarify visualization comprehension, techniques based on saliency maps are applied such as the "pop-out" effect shown in Fig. 4. This concept aims at creating a contrast between an element to underline from its context. The pop-out is built on four parameters: a variation of color, intensity, orientation (Martin, 2018; Chiaramonte, 2007; Wolfe \& Horowitz, 2004) or motion applied to the object (Regan, 1986). However, working with a virtual city model where buildings and street furniture are accurately located, animating an element is irrelevant. In addition, rotating an item is geographically false, and in a situation where all objects have various orientation, a "pop-out" effect would have no impact. Therefore, only two parameters are feasible : color and intensity. An example is shown in Fig. 5.

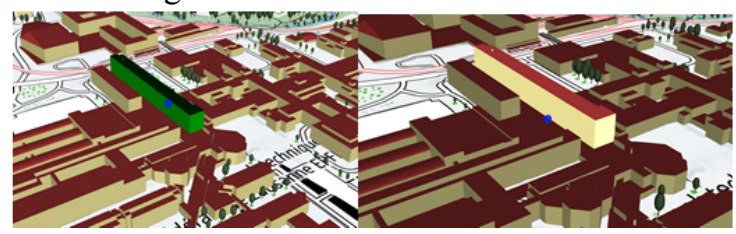

Figure 5. Pop-out effect on a city model from our 3D participatory platform.

Factors such as expertise, age, background or preferences have a direct influence on the user spatial features perception (Newell \& Canessa, 2018), nevertheless, tools exist to limit their impact. The following challenge can be put forward:

[C5] How to design a system that takes into account user features in order to adjust the virtual scene accordingly?

\section{A conceptual framework for $3 D$ participation platform}

Participatory processes are regularly built around ethical, political and economic factors which affect communication dynamics. The starting point of our framework is a request by a decision maker about an urban project. The first step aims at translating his needs to a list of 
understandable information that can be surveyed with the citizens. The urban project pattern and its temporality should be addressed at this stage in order to apprehend the scope of the context which is defined by parameters such as: public latitude, parameters in negotiation, participation type (passive, consultative, interactive), spatial scale, etc. Descriptions of this step can be found in the literature as purpose and context comprehension (also defined as when?) (Bryson \& al., 2012; Lovett \& al., 2015; Marzouki \& al., 2017). Once the needs are formalized, an opinion poll attempts to delimit the scope of participation, adopts the communication tone with citizens, design a scenario, and defines rules. Then, this participation schema has to be technically implemented by selecting interactions between the platform and the users, the available tools and visualization settings (level of detail, transparency, displayed elements, realism, etc). This step illustrates two elements specifying the content and symbology (or what?) and identifying appropriate participation tools (or how?) (Bryson \& al., 2012; Lovett \& al., 2015; Marzouki \& al., 2017). These technical choices lead to the creation of a unique dynamic, where the platform manages iterative interactions between citizens/users, the 3D scene and the translated requests from the authorities. Emotional maps (2D geo-tagging of personal experiences) (Pánek, 2018), argumentation maps (public geo-discussions) (Rinner, 1999), compare and vote on 3D mock-ups (agency9.com), or geo- referenced picture sketching (unli-diy.org) are some examples for potential use and design alternatives. A large amount of raw data from the platform are gathered into a database, introducing a new issue :

[C6] How to handle raw data from participation.

The collected information is not usable as it stands by authorities to take advised decisions. A last translation step is required to transform raw data into convenient, transparent and neutral information for the decision maker. Data visualization and analysis can enhance outcome interpretations. Heat maps illustrating opinions (positive or negative) or categories (security, leisure, meetings, ...) are commonly employed. But other witty portrayals emerge, such as positive and negative discussion sunburst charts sorted by insights (cartodebat.com), or indicators regrouped on a dashboard.

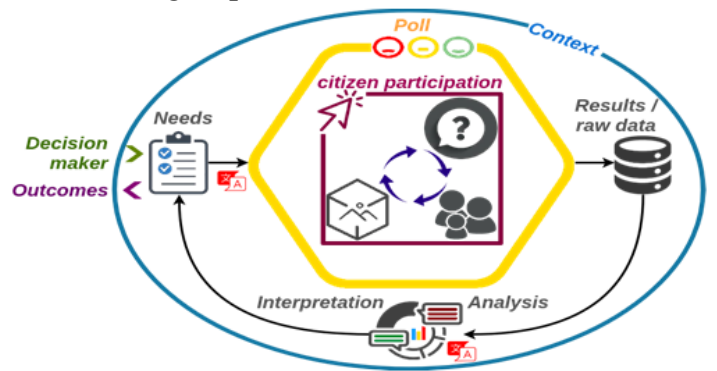

Figure 6. Framework illustrating the design of a 3D participatory platform.

\section{Recommendations addressing identified challenges}

The challenges sketched in this paper can be addressed by three precepts: (1) Responsiveness, platform shapeshift in accordance with the context $[\mathbf{C 1}, 3,5]$, (2) Portrayal, understandable data visualization $[\mathbf{C 1}, \mathbf{2}, \mathbf{3}, \mathbf{5}]$ and (3) Accountability, honest and transparent outcomes [C4,6]. The purpose of this section is to draw recommendations that should tackle each issue.

[C1] Based on the work of (Alexander \& al., 1977), we suggest to use the design pattern theory. Each project type has its specificities (time \& space), identifying a motif applied in accordance with the situation that should simplify the platform design. Moreover, the scene portrayal should tend to an abstract representation for large scale and realist depiction for a smaller scale. Project surroundings are essential for 3D understandings, however, an omission or a verismo representation introduces confusion in the user's view.

[C2] Design a scenario that eases participation for users. For each step of the scenario, parameters and instructions (cameras, space limitation, representation, etc.) could be described to the participants, informing them when a scale is shifted. Static structural city elements can provide robust landmarks to the user. Another method to keep the user perspective is to apply intermediate repre- sentations demonstrated in 2D (Dumont, \& al., 2018).

[C3] Interaction degree and scene representation should vary according to the circumstances. New elements could be highlighted using colors, details, or saturation. Interaction freedom should depend on the degree of participation. For passive participation, we advocate for free navigation in the $3 \mathrm{D}$ scene and for controlled information display. For a consultative level, we suggest to adopt 3D geo-questionnaires, categorized landmarks or geo-discussions (Haklay \& al., 2018). For an interactive degree, we recommend collecting participant insights via sketches, 3D mock-ups or spatial descriptions.

[C4] Designing a flexible and durable 3D platform allows for reusing it in different contexts and thereby reducing costs. Transparency and neutrality, the main concepts of public participation, lead to increasing authority's accountability and project acceptance rates. Encouraging the wisdom of crowds and public judgment deepens the outcome value (Brown, 2015). Furthermore, the inclusion of gamification elements such as stories or rankings is likely to increase the number of users in par- ticipatory processes and the quantity of posts per users.

[C5] Reality 3D abstract representations are shaped by numerous factors related to users (expertise, age, background, color blindness), scales, objectives, contexts, and resources (Warren-Kretzschmar, Tiedtke, 2005). They provide a specific scene understanding which may differ according to the user. Decisive elements for public judgments cannot should not change, however, this does not apply to every component of the scene. Thus, user preferences could be taken into account. Based on the work of Christophe (2008), we recommend to use a dialogue agent that will identify user specificities in order to depict a 3D scene in accordance with his own taste and needs. For instance, a fixed easy to control camera view will be provided to a layperson. 
[C6] Providing understandable, neutral, usable and transparent outcomes from participatory processes are fundamental. These aspects derive from a valuable dataset that has to be exhaustive, up-to-date and accurate. Data collected from the platform (user information, interactions, and inputs) are difficult to process. Modern big data techniques could be applied in order to classify and visualize this kind of information. We also suggest to use deep-learning approaches, natural language processing, image classification, etc.

\section{The future of participatory processes}

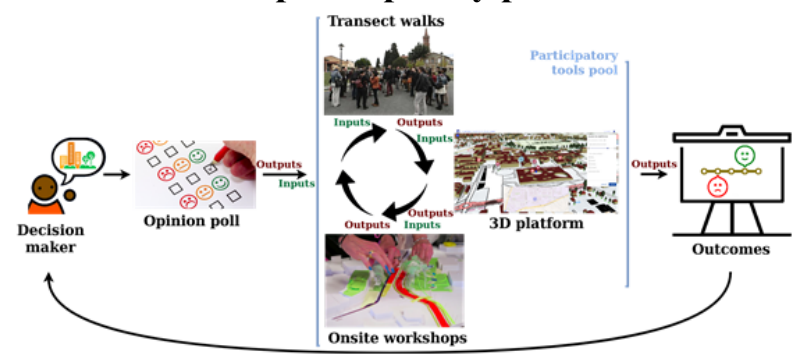

Figure 7. The combination of on-site workshops, transect walks, a 3D platform and other tools at the core of a citizen engagement process.

The collected data (maps, a geospatial database, indicators, comments, etc.) provides input for a Strengths/ Weaknesses/ Opportunities/ Threats (SWOT) analysis, for city strategies and urban studies (Pánek, 2018). These participatory tools advertised for a large public lead to a democratization of the citizen's attention concerning urban planning. Additionally, participant's insights counter- balance urban planner studies. Indeed, the expert vision is efficient but specialized, involving a propensity of seeing public spaces in a professional approach. On the other hand the implication of non-experts in public engagement processes leads to the identification of opinions regarding city features that experts can miss.

Fig. 7 shows another interest of using a 3D participatory platform: its output can be used as an input for other participatory tools. Following a request from the decision maker, an opinion poll is usually performed. This step allows to focus on future participatory discussions by categorizing the expected answers of the citizens. The most common answers are adopted for the next step in the process. Thereafter, we suggest to take advantages of the participation's various shapes such as transect walks (a group of participants follows a pathway in the city to argue about hot-topics), onsite workshops or public hearings, web tools (3D virtual globes), or others means which should, if operated simultaneously, enhance the overall outcomes. The iterative use of the different participatory forms increases accurate feedback for the decision maker's initial requests. In addition, potential biases introduced by the 3D platform or the other participatory means can be limited by combining diverse means. For instance, 3D views which can be considered attractive for younger people tend to exclude elderly people. However, this tendency is counter- balanced by public hearings or urban promenade attendances where the elderly are over-represented. Moreover a mix of participation tools allows for a democratization of public engagement and thereby reaching a larger part of the population.

\section{Conclusions}

The described challenges extend the idea of participation processes. They take into account varying criteria such as spatial/ temporal scales, citizens/ users, and data processing. To confront these challenges a flexible and durable platform needs to be developed. Virtual globe technologies allowing scale changing and personalized functionality are a feasible solution. Prebuilt features can be dynamically activated and adapted depending on the project.

The concept of "digital cities" changes the way how public administrations operate. The fact that new tools offer ways for citizens to react and to take position represents a shift from top-down to bottom-up approaches. This concept places citizen and participatory processes at the heart of the decision making process. However, many existing tools are still not suitable for these new dynamics. Therefore, new participatory platforms should be developed and included in citizen engagement pro- cesses. This kind of neutral tools can help the citizens to understand a project's objectives and constraints and to guide them to create their own opinion in order to influence political decisions. On the other hand such platforms can be helpful for decision makers to take decisions that are accepted by a majority of the population.

\section{References}

Alatalo, T., Pouke, M., Koskela, T., Hurskainen, T., Florea, C., \& Ojala, T. (2017). Two real-world case studies on 3D web applications for participatory urban planning. In Proceedings of the 22nd International Conference on 3D Web Technology - Web3D '17, 1-9.

Alexander, C., Ishikawa, S., Silverstain, M., Jacobson, M., Fiksdahl-King, I., \& Angel, S. (1977). A Pattern Language : Towns, Buildings, Construction. New York, Oxford University Press.

Appleton, K., \& Lovett, A. (2003). GIS-based visualisation of rural landscapes: defining 'sufficient' realism for environmental decision-making. Landscape and Urban Planning, 65, 117-131.

Arab, N. (2007). Activité de projet et aménagement urbain : les sciences de gestion à l'épreuve de l'urbanisme. Management \& Avenir, 12, 147.

Arnstein, S. R. (1969). A Ladder Of Citizen Participation. Journal of the American Institute of Planners, 35, 216224.

Biljecki, F., Stoter, J., Ledoux, H., Zlatanova, S., \& Çöltekin, A. (2015). Applications of 3D City Models: State of the Art Review. ISPRS International Journal of Geo-Information, 4, 2842-2889.

Bowman, D. A., Koller, D., \& Hodges, L. F. (1997). Travel in Immersive Virtual Environments: An Evaluation of Viewpoint Motion Control Techniques. In Virtual Reality Annual International Symposium.

Brown, G. (2015). Engaging the wisdom of crowds and public judgement for land use planning using public 
participation geographic information systems. Australian Planner, 52, 199-209.

Bryson, J., Quick, K. S., Slotterback, C. S., \& Crosby, B. C. (2012). Designing Public Participation Process. Public Administration Review, 73, 23-34.

Bugs, G., Granell, C., Fonts, O., Huerta, J., \& Painho, M. (2010). An assessment of Public Participation GIS and Web 2.0 technologies in urban planning practice in Canela, Brazil. Cities, 27, 172-181.

Chapon, P.-M., Beuret, C., Bolomier, C., Choisy, P., \& Zambernardi, S. (2010). Cartes mentales et représentations spatiales de résidants en MARPA : un outil d'aide à l'implantation de nouvelles structures d'hébergement ? Norois, (216), 57-66.

Chiaramonte, C. (2007). Attraction de l'attention par des différences relatives de familiarité : étude expérimentale de la dynamique des processus précoces.Université Pierre Mendès France (Grenoble).

Christophe, S. (2008). Legend Design on the Web: Creating Accurate Styles. International Journal of Spatial Data Infrastructures Research, 3, 38-57.

Çöltekin, A., Lokka, I., \& Zahner, M. (2016). On the usability and usefulness of $3 \mathrm{~d}$ (geo)visualizations; a focus on virtual reality environments. ISPRS International Archives of the Photogrammetry, Remote Sensing and Spatial Information Sciences, 387-392.

Downes, M., \& Lange, E. (2015). What you see is not always what you get: A qualitative, comparative analysis of ex ante visualizations with ex post photography of landscape and architectural projects. Landscape and Urban Planning, 142, 136-146.

Dumont, M., Touya, G., \& Duchêne, C. (2018). Alternative transitions between existing representations in multi-scale maps. Proceedings of the ICA, 1, 1-4.

Evans-Cowley, J., \& Hollander, J. (2010). The New Generation of Public Participation: Internet-based Participation Tools. Planning Practice \& Research, 25, 397-408.

Goodchild, M. F. (2007). Citizens as sensors: the world of volunteered geography. GeoJournal, 69(4), 211-221.

Haklay, M., Jankowski, P., \& Zwoliński, Z. (2018). Selected modern methods and tools for public participation in urban planning - a review. Quaestiones Geographicae, 37(3), 127-149.

Hart, R. (1992) Children's Participation: From Tokenism to Citizenship, UNICEF Innocenti Essays No. 4.

Hayek, U. W. (2011). Which is the Appropriate 3D Visualization Type for Participatory Landscape Planning Workshops? A Portfolio of Their Effectiveness. Environment and Planning B: Planning and Design, 38, 921-939.

Herman, L., Juř́k, V., Stachoň, Z., Vrbík, D., Russnák, J., \& Řezník, T. (2018). Evaluation of User Performance in Interactive and Static 3D Maps. ISPRS International Journal of Geo-Information, 7, 415.
IAP2 (2014) [International Association of Public Participation] IAP2's Public Participation Spectrum, IAP2 International Federation. www.iap2.org (2019)

Jankowski, J., Hulin, T., \& Hachet, M. (2014). A Study of Street-level Navigation Techniques in 3D Digital Cities on Mobile Touch Devices. IEEE 3DUI Symposium on 3D User Interfaces, 35-38.

Jankowski, J., \& Hachet, M. (2015). Advances in Interaction with 3D Environments. Computer Graphics Forum, 34, 152-190.

Julin, A., Jaalama, K., Virtanen, J.-P., Pouke, M., Ylipulli, J., Vaaja, M., ... Hyyppä, H. (2018). Characterizing 3D City Modeling Projects: Towards a Harmonized Interoperable System. ISPRS International Journal of Geo-Information, 7, 55.

Juřík, V., Herman, L., Kubíček, P., Stachoň, Z., \& Šašinka, Č. (2016). Cognitive aspects of collaboration in $3 \mathrm{~d}$ virtual environments. ISPRS - International Archives of the Photogrammetry, Remote Sensing and Spatial Information Sciences, 663-670.

Lange, E. (2011). 99 volumes later: We can visualise. Now what? Landscape and Urban Planning, 100, 403 406.

Liao, H., Dong, W., Peng, C., \& Liu, H. (2017). Exploring differences of visual attention in pedestrian navigation when using 2D maps and 3D geo-browsers. Cartography and Geographic Information Science, 44, 474-490.

Lokka, I. E., \& Çöltekin, A. (2018). Evaluating route learning performance of older and younger adults in differently-designed virtual environments: a taskdifferential analysis. ISPRS - International Archives of the Photogrammetry, Remote Sensing and Spatial Information Sciences, 383-387.

Lovett, A., Appleton, K., Warren-Kretzschmar, B., \& Von Haaren, C. (2015). Using 3D visualization methods in landscape planning: An evaluation of options and practical issues. Landscape and Urban Planning, 142, 85-94.

Lynch, K. (1960). The image of the city. MIT press.

Mackinlay, J. D., Stuart K., C., \& Robertson, G. G. (1990). Rapid, Controlled Movement Through a Virtual 3D Workspace. Computer Graphics, 24.

Martin, H. (2018). Maquette numérique 3D pour la construction : visualiser les connaissances métier et interagir avec des dispositifs immersifs.

Marzouki, A., Mellouli, S., \& Daniel, S. (2017). Towards a Context-based Citizen Participation Approach : a Literature Review of Citizen Participation Issues and a Conceptual Framework. ICEGOV '17 Proceedings of the 10th International Conference on Theory and Practice of Electronic Governance, 204-213.

McCrae, J., Mordatch, I., Glueck, M., \& Khan, A. (2009). Multiscale 3D navigation. Proceedings of the 2009 Symposium on Interactive 3D Graphics and Games I3D ’09, 7-14.

Midler C. (1993), L'auto qui n'existait pas, InterEditions. 
Montello, D. R. (1993). Scale and Multiple Psychologies of Space Daniel. COSIT 1993: Spatial Information Theory A Theoretical Basis for GIS, 312-321.

Moya, S., Grau, S., \& Tost, D. (2014). First-Person Locomotion in 3D Virtual Environments: a Usability Analysis. Journal of Universal Computer Science, 20, 1026-1045.

Méricskay, B. (2012). Cartographie en ligne et planification participatory. Analyse des usages du geoweb et d'Internet dans le débat public à travers le cas de la ville de Québec.

Newell, R., \& Canessa, R. (2018). From sense of place to visualization of place: examining people-place relationships for insight on developing geovisualizations. Heliyon, 4.

Onitsuka, K., Ninomiya, K., \& Hoshino, S. (2018). Potential of 3D Visualization for Collaborative Rural Landscape Planning with Remote Participants. Sustainability, 10.

Pánek, J. (2018). Emotional Maps: Participatory Crowdsourcing of Citizens' Perceptions of Their Urban Environment. Cartographic Perspectives, 0(90).

Parush A., Ahuvia S., Erev I. (2007) Degradation in Spatial Knowledge Acquisition When Using Automatic Navigation Systems. In: Winter S., Duckham M., Kulik L., Kuipers B. (eds) Spatial Information Theory. Lecture Notes in Computer Science, vol 4736.

Pretty, J. N. (1995). Participatory learning for sustainable agriculture. World Development, 23, 1247-1263.

Regan D (1986) Form from motion parallax and form from luminance: Vernier discrimination. Spatial Vision $1: 305-318$

Rinner, C. (1999). Argumaps for spatial planning. Proceedings of TeleGeo'99, First International Workshop on Telegeoprocessing, 95-102.

Seipel, S. (2013). Evaluating 2D and 3D geovisualisations for basic spatial assessment. Behaviour \& Information Technology, 32, 845-858.

Stachoň, Z., Kubicek, P., Málek, F., Krejčí, M., \& Herman, L. (2018). The Role of Hue and Realism in Virtual Reality. 7th International Conference on Cartography and GIS.

Subra, P. (2014). Géopolitique de l'aménagement du territoire, Armand Colin (2ème édition), 350 pages

Tutzauer, P., Becker, S., Niese, T., Deussen, O., \& Fritsch, D. (2016). Understanding human perception of building categories in virtual $3 \mathrm{~d}$ cities - a user study - A USER STUDY. ISPRS - International Archives of the Photogrammetry, Remote Sensing and Spatial Information Sciences, 683-687.

United Nations. (2014). World Urbanization Prospects. Economic \& Social Affairs.

Warren-Kretzschmar, B., \& Tiedtke, S. (2005). What Role Does Visualization Play in Communication with Citizens? - A Field Study from the Interactive
Landscape. Trends in Real-Time Landscape Visualization and Participation, 156-167.

Wolfe, J. M., \& Horowitz, T. S. (2004). What attributes guide the deployment of visual attention and how do they do it? Nature Reviews Neuroscience, 5, 495-501.

Zhang, X. (Luke). (2009). Multiscale traveling: crossing the boundary between space and scale. Virtual Reality, $13,101-115$. 